\title{
Dendrimers toward Translational Nanotherapeutics: Concise Key Step Analysis
}

Serge Mignani, * Xiangyang Shi, * João Rodrigues, René Roy, Ángeles Muñoz-Fernández, Valentin Ceña, and Jean-Pierre Majoral*

Cite This: Bioconjugate Chem. 2020, 31, 2060-2071

ABSTRACT: The goal of nanomedicine is to address specific clinical problems optimally, to fight human diseases, and to find clinical relevance to change clinical practice. Nanomedicine is poised to revolutionize medicine via the development of more precise diagnostic and therapeutic tools. The field of nanomedicine encompasses numerous features and therapeutic disciplines. A plethora of nanomolecular structures have been engineered and developed for therapeutic applications based on their multitasking abilities and the wide functionalization of their core scaffolds and surface groups. Within nanoparticles used for nanomedicine, dendrimers as well polymers have demonstrated strong potential as nanocarriers, therapeutic agents, and imaging contrast agents. In this review, we present and discuss the different criteria and parameters to be addressed to prepare and develop druggable nanoparticles in general and dendrimers in particular. We also describe the major requirements, included in the preclinical and clinical roadmap, for NPs/dendrimers for the preclinical stage to commercialization. Ultimately, we raise the clinical translation of new nanomedicine issues.

$\mathrm{F}$ rom the beginning of human history, many attempts have been made to improve and extend the quality of life in our society. An important point in medical care is the improvement of the patient's ability to fully enjoy normal life activities in both family and work life. ${ }^{\top}$ Technology and medicine have gone hand and hand, and medical technology has made remarkable advances and supports patients in the checking and diagnosis of their diseases, and has consequently saved millions of lives. Nanomedicine has the potential to revolutionize medicine and drug development. The major nanomedicine fields include neurological, oncological, cardiovascular, anti-inflammatory, and anti-infective therapeutic applications. On the basis of the Grand View Research report (2020), the global nanomedicine market size will reach US $\$ 350.8$ billion in 2025 with a compound annual growth rate (CAGR) of $11.2 \%$. $^{2}$

During the past decade, within the precision medicine realm, medical technology advances have allowed doctors to select medicines and therapies and predict which treatments will work best for specific patients. In the therapeutic field, this emerging approach for disease treatment and prevention takes into account individual genetic profile variability, environment, and lifestyle. For instance, in oncology, the best patient-precise treatment attacks tumors based on the patient's specific gene mutations and protein expressions. In addition, precision medicine includes diagnostics for imaging and identification purposes. $^{3}$
In order to help overcome problems in medicine, the very active field of nanomedicine, including nanoscience and nanotechnology in a more broad sense, has captured widespread attention and imagination, and it represents a vast interdisciplinary research field. ${ }^{4}$ These disciplines have expanded rapidly and widely, encompassing chemistry, biology, physics, and engineering, among others. Nanomedicine has appeared to be a benefit to humanity in a wide variety of multidisciplinary domains, such as in the treatment of cancer, ${ }^{5}$ cardiovascular disease, ${ }^{6}$ and central nervous system disorders. ${ }^{7}$

Polymer therapeutics as well polymers as drugs and proteinconjugates have been developed as early as 2001. The use of nanoparticles (NPs) as nanocarriers has enhanced the bioavailability, pharmacokinetics (PK) of drugs for better absorption, distribution, metabolism, and excretion (ADME), as well as favorable pharmacokinetic/pharmacodynamic (PK/ $\mathrm{PD})$ properties. The understanding of $\mathrm{PK} / \mathrm{PD}$ parameters is crucial in the regulatory approval process. ${ }^{8}$

Received: July 8, 2020

Revised: July 31, 2020

Published: August 10, 2020

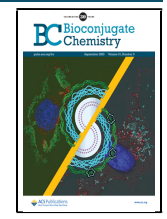


In the overwhelming active field of NPs as "intelligent" nanocarriers, there are targeting profiles and controlled-release profiles of loaded drugs, as well as less systemic toxicity, alone and in combination with an approved drug, thus inducing possible changes in the ADME of the drug. ${ }^{9}$ In addition, NPs are not only used for "classical" drug delivery but also for the delivery of genes ${ }^{10}$ and for imaging purposes. ${ }^{11}$

NPs are now reproducibly prepared with highly monodisperse properties and with controllable and tunable structural parameters, such as sizes, shapes, and surface chemistries that mimic critical biological macromolecules, including proteins, RNA/DNA, viruses, oligonucleic acids, carbohydrates, and other cellular components. ${ }^{12}$ It is important to note that the nature of nanoscale characteristics of NPs suggests the possibility of novel interactions with cells, tissues, organs, and therapeutic disease sites. ${ }^{13}$ In addition, the personalized nanomedicine approach and companion diagnostics to theranostics have been developed in order to identify the best treatment plan. This strategy links therapeutic or/and diagnostic agents. ${ }^{14}$ The goal of the therapy is to develop the right therapy for the right patient, given at the right time. The understanding of the disease and the genetic sequencing allows the selection of particular patients. Much of the progress in the field of theranostics has been made in oncology, ${ }^{15}$ reflecting the complexity and variability of the diseases in individuals. In addition, this field is based on the open innovation research partnership strategy, which reduces research costs, but the expertise and knowledge needed to develop and market drugs remain in the hands of the pharmaceutical industry.

\section{NANOTECHNOLOGICAL APPROACHES IN NANOMEDICINE FOR CHRONIC DISEASES}

In order to circumvent several challenges and drawbacks in drug development, nanotechnological approaches have been developed for the treatment of chronic diseases, ${ }^{16}$ for example, cancer, and recently against COVID-19. ${ }^{17}$ Various NPs have been conceived and developed as important and powerful strategies for the targeted delivery (also named "magic bullet" therapy) of conventional drugs, ${ }^{18}$ recombinant proteins, vaccines, aptamers, siRNAs, nucleotides, and genes.

In particular, alongside polymeric NPs, which are the first (1970s) NP-based nanomedicines, solid-lipid, magnetic and metal based NPs, polymeric micelles, and linear polymers were developed. ${ }^{19}$ Four major classes of polymer architectures relative to polymeric NPs (linear, cross-linked, branched and dendritic) were highlighted and discussed by Seo and Hawker. ${ }^{20}$

The clinical relevance of NP types include self-assembled systems such as liposomes, ${ }^{21}$ micelles, and polymeric/ micelles, ${ }^{22}$ processed NPs such as emulsions, chemically bound NPs such as dendrimers, protein-based NPs, iron oxide, silica, and gold NPs. The number of marketed nanodrugs is expected to grow continuously; a total of 27 are currently clinically approved for intravenous therapies and diagnostics, and 81 intravenous NPs are currently under clinical trials to increase the likelihood to treat diseases and to improve the living conditions of patients. ${ }^{23,24}$

Despite important worldwide efforts over the last three decades, only a few NPs have been approved by the Food and Drug Administration (FDA) and European Medicines Agency (EMA). The FDA approved 51 nanomedicines by 2016, among which $40 \%$ were in clinical trials between 2014 and 2016. The first FDA approved (1990) was the Adagen/pegademase bovine (Sigma-Tau Pharmaceuticals) and in 2015 was ADYNOVATE
(Baxalta). In the case of EMA, 34 nanomedicines were approved. The first approved nanotherapeutics were liposomal drugs (encapsulation of drugs) or linear polymer (PEG type)drug conjugates (conjugation of drugs). Between 1995 and 2014, the FDA approved 9 nanomedicines, and 14 were in clinical trials. In the oncology realm, two major NPs are used in the clinic: Doxil and Caelyx (Doxorubicin $\mathrm{HCl}$ (Adriamycin) pegylated liposome injection) and Abraxane. Doxil was the first FDA-approved nanodrug in 1995, and recently a generic named Lipodox (Sun Pharmaceutical Industries LTD) has been FDAapproved. The other liposomal formulations of doxorubicin are D-99, Myocet, the thermosensitive liposome ThermoDox, and polymeric nanoparticles, Livatag, whereas the liposomal of daunorubicin is named DaunoXome. The second interesting NP is Abraxane. Taxanes in general and Taxol in particular represent an important class of potent antitumor agents, for instance, against early stage breast cancer, but the clinical advances of taxanes have been limited by their high hydrophobicity. To overcome its poor water solubility, new systemic formulations have been developed. For instance, albumin-bound Taxol (Abraxane) from Abraxis BioScience and AstraZeneca represents an original cremophore-free NP showing strong antitumor activity when associated with radiotherapy in a supra-additive manner. Doxil/Caelyx and Abraxane are mentioned in over 160 and 290 clinical studies, respectively. ${ }^{23-26}$ In order to define nanomaterials and NPs, an FDA guidance document has been published based on two points to be considered: (1) developing a material or a final product having at least one external dimension, or internal or surface structure in the nanoscale range $(\sim 1-100 \mathrm{~nm})$ or $(2)$ exhibiting properties such as physical or chemical properties or biological effects related to its dimension(s), even if those NPs have a nanoscale range up to $1000 \mathrm{~nm}^{27-29}$

\section{DENDRIMERS IN NANOMEDICINE}

In recent decades, a new class of discrete polymeric materials, i.e., dendrimer-based nanomedicine, has aroused great interest in nanomedicine. ${ }^{30,31}$ These dendrimers, with branched layers resembling an onionskin, have been very well described as one of the most tunable nanomaterials for both therapeutic and diagnostic applications. Dendrimers are used either as nanocarriers for biologically active agents (most examples) ${ }^{32}$ or as active drugs in themselves (few examples). ${ }^{33-35}$ Moreover, only dendrimeric NPs are suitable for a wide variety of routes of administration, from intravenous to intranasal, transdermal and ocular, and can be used for active or passive drug targeting. ${ }^{36,37}$

The main biophysical attributes of dendrimers, in general, are (1) biocompatibility; (2) biodegradability; (3) ready functionalization onto the surface for targeting, therapy and imaging purposes; (4) monodispersity; (5) safety everywhere in the body with a high therapeutic window; (6) nonimmunogenicity; and (7) precisely controllable dimensions and architectures. ${ }^{38}$ Some of dendritic NPs are commercially available, such as poly(amidoamine) (PAMAM) and poly(propyleneimine) (PPI). Interestingly, multifunctional dendrimers can be used for a wide range of biomedical applications, including intracellular delivery of small and large molecules, such as cyclic peptides, ${ }^{39}$ in gene delivery domain ${ }^{40}$ including for instance nucleic acid drugs, ${ }^{41}$ antisense oligonucleotides ${ }^{42}$ short hairpin RNA, ${ }^{43}$ small interfering RNA, ${ }^{44}$ antibodies, ${ }^{45}$ and aptamers. ${ }^{46}$

The use of dendrimers as nanocarriers takes particular advantage of the water solubility of dendrimers that have been decorated with suitable hydrophilic functions. For example, the 
introduction of polyethylene glycol (PEG) groups and zwitterions provides water solubility and stability and prolongs the blood circulation of multifunctional dendrimers. Recently, a very interesting review was published by Tomalia et al. regarding the crucial role of branch cell symmetry features in the design parameters (e.g., internal packing mode, densities, refractive indices, interior porosities) of the properties of dendrimer encapsulation. ${ }^{47}$ Two branch cell symmetry feature were described: symmetrical branch cell dendrimers (category I) with interior void space, and asymmetrical branch cell dendrimers (category II) showing no interior void space.

Table 1 shows the major advantages of multifunctional dendrimers as nanocarriers and active per se in nano-

Table 1. Major Advantages of Multifunctional Dendrimers As Nanocarriers and Therapeutic Agents in Nanomedicine

1. Reduce the dosage of drugs and surgical procedures

2. Modulation of $\mathrm{PK} / \mathrm{PD}$ properties

3. Increased treatment efficacy related to unsolved medical problems

4. Controlled biodistribution

5. Decreased drug side effects and reduced mortality and morbidity

6. Increased drug delivery to the exact location

7. Easy to detect with a fluorescent probe as sensitive diagnostic tools

8. Improved patient compliance by reducing unmet medical need

9. Multiple routes of administration (e.g., intravenous (iv), intraperitoneal (ip), ocular, transdermal, oral (po), intranasal, and pulmonary)

10. High drug loading capacity (local concentration effect)

11. Easy to detect (fluorescent probe) as sensitive diagnostic tools

12. Enhanced permeability and retention (EPR) effect ${ }^{50}$ for the accumulation of NPs in tumor tissues. Currently, this concept is challenged: "the EPR effect works in rodents but not in humans!"

13. Dendrimer encapsulation properties ${ }^{47}$ medicine. ${ }^{48,49}$ The main disadvantages of dendrimers can be summarized as follows: (1) a lack of knowledge about the effects of dendrimers on biochemical pathways and processes in the human body, (2) a lack of knowledge about toxicity characterization and exposure pathways, (3) cost for dendrimers of high generations, (4) implementation issues, and (5) engineering of multifunctional dendrimers.

The targeted dendrimer strategy is in line with the personalized medicine approach and includes diagnostic (imaging and identification) and therapeutic areas (delivering drugs to the exact location, killing cancer cells, bacteria, and viruses, among others, and repairing damaged tissues). Most dendrimers are used as nanocarriers of small and large molecules, genes and peptides, and can have the following positive attributes: (1) good diffusion out of the blood vessels; (2) good internalization into target cells, for instance, inducing selective tumor accumulation and reducing volume of distribution $(\mathrm{Vd})$; (3) clear body safety; (4) increase in the therapeutic potency of carried drugs by proper recognition of the target cells, improving their stability under physiological conditions, improving aqueous solubility, enhancing PK/PD behavior compared to small molecule drugs which showed large $\mathrm{Vd}$, preventing their recognition by macrophages (mononuclear phagocytic system) and elimination by the reticuloendothelial system, increasing their circulating half-life and selective passive diffusion through increased permeability and retention, (5) maintain good drug stability in body fluid, (6) allow unconventional routes of administration overcoming, for instance, poor oral bioavailability that include crossing the blood barrier (BBB), and (7) tunable surface of dendrimers for controlledrelease delivery, for instance, for tumor targeting. ${ }^{52}$ These attributes can also be analyzed for dendrimers active per se. ${ }^{12}$

Core:

Molecular information region: size, 3D shape, directionally and multiplicity of branching
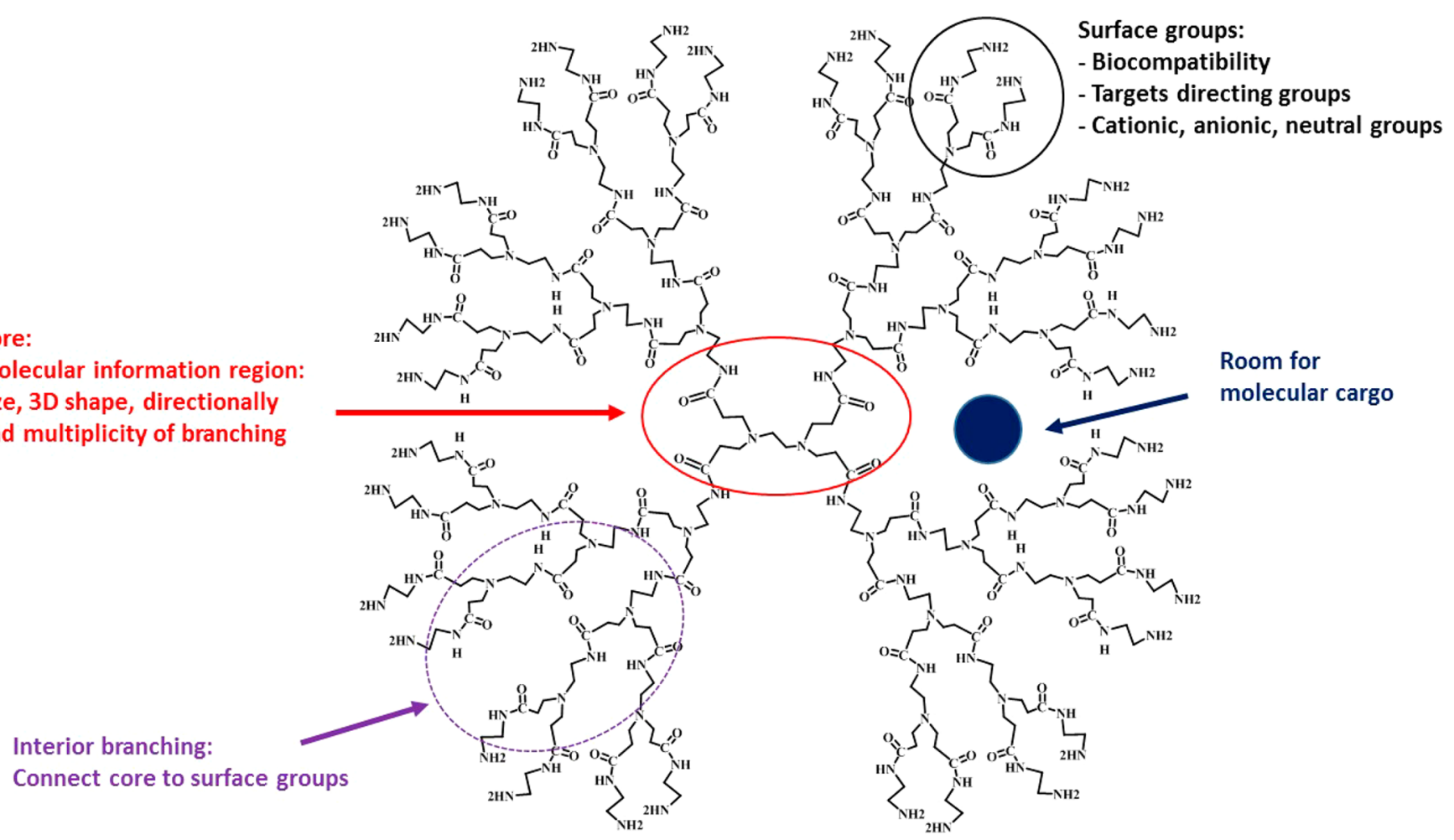

Figure 1. Two-dimensional chemical structure of G4 PAMAM dendrimers with the different characteristics such as core, surface, void space, and interior branching. 


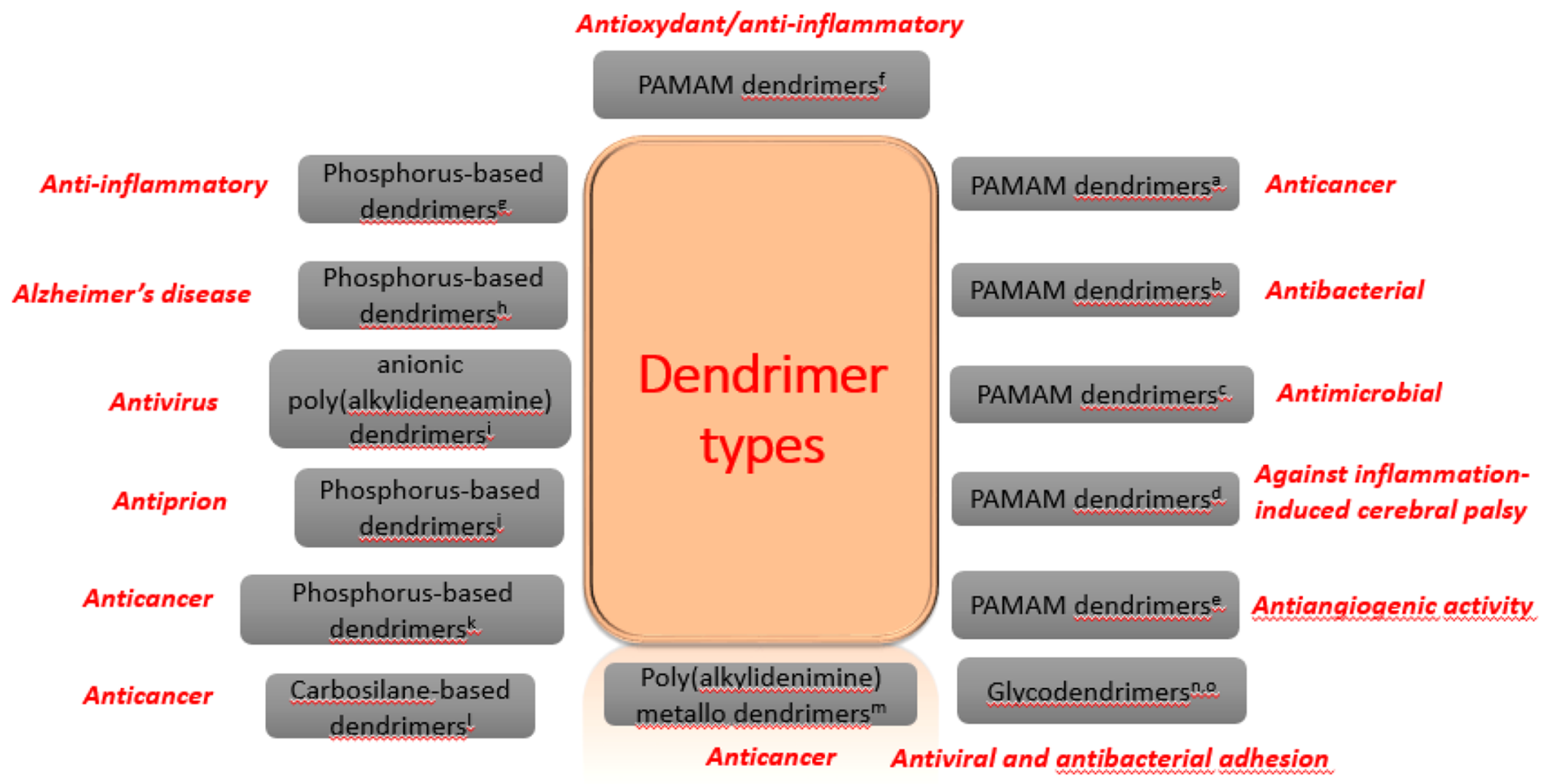

Figure 2. Selected examples of therapeutic areas using dendrimers as drugs. For representative examples: $a,{ }^{57} b,{ }^{58} c,{ }^{59} d,{ }^{60} e,{ }^{61} f,{ }^{62} g,{ }^{55} h,{ }^{63} i,{ }^{64} j,{ }^{65} k,{ }^{66}$ $1,{ }^{67} \mathrm{~m},{ }^{68} \mathrm{n},{ }^{69} \mathrm{o}^{70}$

Figure 1 presents the 2D chemical structure of G4 PAMAM dendrimers, as an example of dendrimer showing different characteristics that include the core, surface functionality, void space and interior branching, whereas Figure 2 shows selected examples of therapeutic areas using some dendrimers as drugs, and a few example, for instance phosphorus dendrimers, were described to date. ${ }^{53}$ It is important to note, as selected examples, that several biocompatible phosphorus dendrimer types showed good in vivo activities as anticancer agents, ${ }^{54}$ anti-inflammatory agents, $^{55}$ and for gene delivery. ${ }^{56}$ using several route of administration including, i.v. and inhalation. PAMAM, PPI, and bow-tie dendrimers as nanocarriers of anticancer drugs displayed also in vivo activities in the oncology domain. ${ }^{57}$

\section{DRUGGABILITY OF DENDRIMERS}

It is obvious that nontoxic biomedical dendrimers are needed for clinical developments as both drug-delivery systems and nanodrugs. The biocompatibility of dendrimers represents an important factor for their biomedical applications. The analyses of the different absorption, distribution, metabolism, excretion, and toxicity (ADMET) parameters of dendrimers, as well as their PK/PD parameters, represent key factors for their preclinical and clinical developments. ${ }^{71,72}$ For instance, the determination of adequate exposure, based on PK/PD behaviors over the clinical objectives, is a critical goal to be achieved. In this original review, we highlighted key in vivo physicochemical properties, based on data from biochemical, cellular, and animal models, to provide biocompatible dendrimers.

So far, in vitro and in vivo studies have been crucial to evaluate cell viability, hematological toxicity, immunogenicity, biocompatibility, and biodistribution, in order to establish risk/benefit ratio profiles. Several reviews have analyzed in depth the in vitro and in vivo physiological parameters to develop dendrimers in preclinical stages. ${ }^{73,74}$ In vitro ${ }^{71}$ and in vivo ${ }^{72}$ key factor analyses have been highlighted and evaluated by several researchers. A very important review has been published by Kannan, Tomalia et al. ${ }^{75}$ The authors introduced the concept of "nanoperiodic" about the optimization of $\mathrm{PK} / \mathrm{PD}$ profile and site-specific targeting of disease of NPs in general and dendrimers in particular based on their nanoscale design parameters. A useful roadmap depicting in vivo barrier and processing differences between small molecule drugs $(<1 \mathrm{~nm})$ and nanoparticle therapies (approximately $1-100 \mathrm{~nm}$ ) has been presented and discussed. Systemic administration of small molecule drugs $(<1$ $\mathrm{nm}$ ) leads to short circulation times due to fast kidney excretion modes and whole-body permeability, whereas larger nanoscale therapeutics $(>4 \mathrm{~nm}$ ) exhibit (1) longer circulatory residency times, (2) size selective excretion modes, and (3) permeability patterns associated with their nanoscale size and surface chemistry. In vivo dendrimer clearance is mainly dependent on size (i.e., generation level) and surface chemistry. Prolonged blood retention and reduced renal excretion were observed with increases in dendrimer size. Also, to extend the scope of the use of dendrimers, a very interesting analysis of the opportunities and challenges of multifunctional dendritic polymers in nanomedicine has been emphasized by Haag and colleagues. ${ }^{12}$ The "Holy Grail" in nanomedicine is to design and synthesize new advanced macromolecular nanocarriers and to translate them from the lab to the clinic. Very recently, Choi et al. recommended a simple and useful algorithm to guide the ADME properties of nanodrugs. This algorithm provides practical checkpoints for NPs development and assessment before clinical evaluations. $^{23}$

Taken together, physicochemical properties, such as charge, surface properties, shapes, and sizes of dendrimers as well as the routes of administration, strongly influence PK by controlling absorption, distribution, and elimination processes. The final goal is the improvement of the plasma residence times and halflives of dendrimers, whether as nanocarriers or not (e.g., as drugs), as well as their tissue permeation, delivering the drug to the target tissue and avoiding adverse effects. The two main strategies to avoid dendrimer toxicity are based on the design 
Table 2. Major Requirements/Milestones for NPs/Dendrimers from Preclinical Stage to Commercialization

\begin{tabular}{|c|c|c|}
\hline $\begin{array}{l}\text { development } \\
\text { stage }\end{array}$ & objective & major criteria to be analyzed and critical outcomes \\
\hline \multirow[t]{10}{*}{ Discovery } & $\begin{array}{l}\text { Design and development of tunable and biocompatible NPs } \\
\text { for optimal biological application }\end{array}$ & - Size $^{75}$ \\
\hline & & -Stability in biological conditions (in vitro and in vivo) \\
\hline & & -Chemical stability of dendrimers \\
\hline & & -Stability in manufacturing and drug storage process \\
\hline & & -Preliminary scale-up evaluation \\
\hline & & $\begin{array}{l}\text {-Ease of manufacture based on the robust methodology for potential scale-up for } \\
\text { cGMP }\end{array}$ \\
\hline & & -Encapsulation efficiency and adequate release kinetics \\
\hline & & -Physiochemical and biological characterization \\
\hline & & -Quality control \\
\hline & & -Process design \\
\hline \multirow[t]{16}{*}{ Preclinical } & Selection of the NPs with good druggability & -Stability studies \\
\hline & & -Preformulation analytical studies \\
\hline & & $\begin{array}{l}\text {-Evaluation of degradation and elution for oral and } \mathrm{i} v \text { administration. Specifically in the } \\
\text { gastrointestinal (GI) system for oral administration }\end{array}$ \\
\hline & & $\begin{array}{l}\text {-Evaluation of the conversion of the NPs to non-nanomedicines and remaining NPs in } \\
\text { the administration sites }\end{array}$ \\
\hline & & -ADME profile \\
\hline & & $\begin{array}{l}\text {-In vitro therapeutic profile (non-good laboratory practice, GLP): cellular assays, } \\
\text { mechanism of cell uptake, therapeutic loading and release, and therapeutic effect } \\
\text { compared to platform alone (if relevant). }\end{array}$ \\
\hline & & $\begin{array}{l}\text {-In vitro demonstration of the specific mechanism of action of the encapsulated/ } \\
\text { conjugated drug (non-GLP) }\end{array}$ \\
\hline & & -In vivo therapeutic profile (non-GLP) \\
\hline & & $\begin{array}{l}\text {-In vivo pharmacokinetics (non-GLP) showing adequate biodistribution, PK, PK/PD } \\
\text { profiles, good efficacy and safety }\end{array}$ \\
\hline & & $\begin{array}{l}\text {-Toxicity studies (acute dose limiting and chronic dosing, reach off-target effects (toxic } \\
\text { levels) related to concentrations, genotoxicity) (non-GLP) and then toxicity studies } \\
\text { using GLP standardized techniques }\end{array}$ \\
\hline & & -Toxicity of both dendrimers alone and dendrimer/drug \\
\hline & & $\begin{array}{l}\text {-Selection of the route of administration as well the procedure of administration (e.g., } \\
\text { daily dose) and to be stable in the selected formulation }\end{array}$ \\
\hline & & -Scale-up to GMP batch for clinical trials \\
\hline & & -Complexity of the manufacturing process and industrialization standpoint \\
\hline & Studies under good laboratory practice (GLP) & -To be performed during the clinical trials: \\
\hline & & -In vivo toxicokinetics, in vivo safety pharmacology, and in vivo reproductive toxicology \\
\hline \multirow[t]{8}{*}{$\begin{array}{l}\text { IND } \\
\text { application }\end{array}$} & $\begin{array}{l}\text { Needs to be approved by the regulatory agencies (e.g., FDA, } \\
\text { EMA) }\end{array}$ & Information from \\
\hline & & -Preclinical toxicity (FDA/EMA) \\
\hline & & -Formulation for the selected route of administration \\
\hline & & -Animal pharmacology and toxicity (from preclinical studies) \\
\hline & & -Manufacturing information related to composition and stability \\
\hline & & For additional studies to be done, see ref 85 \\
\hline & & Nontoxic with minimal side effects, no significant drug interactions \\
\hline & & At least as effective as current standard or best alternative \\
\hline \multicolumn{3}{|l|}{ Clinical trials } \\
\hline Phase I & $\begin{array}{l}\text { Assess dosing, acute toxicity, and NPs excretion in healthy } \\
\text { humans but in some cases with humans with the disease }\end{array}$ & Testing for therapeutic specific side effects identified in preclinical studies \\
\hline Phase II & Evaluation of the safety and efficacy of NPs in patients & Multiple patient groups and at multiple sites \\
\hline Phase III & $\begin{array}{l}\text { Large, randomizedn placebo-controlled trials to demonstrate } \\
\text { further safety and efficacy and compare the investigational } \\
\text { platform to the gold standard }\end{array}$ & Drug safety and efficacy relative to the gold standard of care. \\
\hline \multirow[t]{7}{*}{$\begin{array}{l}\text { NDA } \\
\text { application }\end{array}$} & $\begin{array}{l}\text { Needs to be approved by the regulatory agencies (e.g., FDA, } \\
\text { EMA) }\end{array}$ & Information from \\
\hline & & -NPs \\
\hline & & -Results of animals studies \\
\hline & & -Clinical trial outcomes \\
\hline & & -NPs behavior in the body \\
\hline & & -NPs manufacturing, processing, and packaging \\
\hline & & -Phase IV strategy studies \\
\hline
\end{tabular}

and synthesis of core and branching units, and to mask peripheral charges by using surface engineering approaches. The right design of tailored dendrimers in light of future clinical applications remains a critical objective to be achieved. Low in 


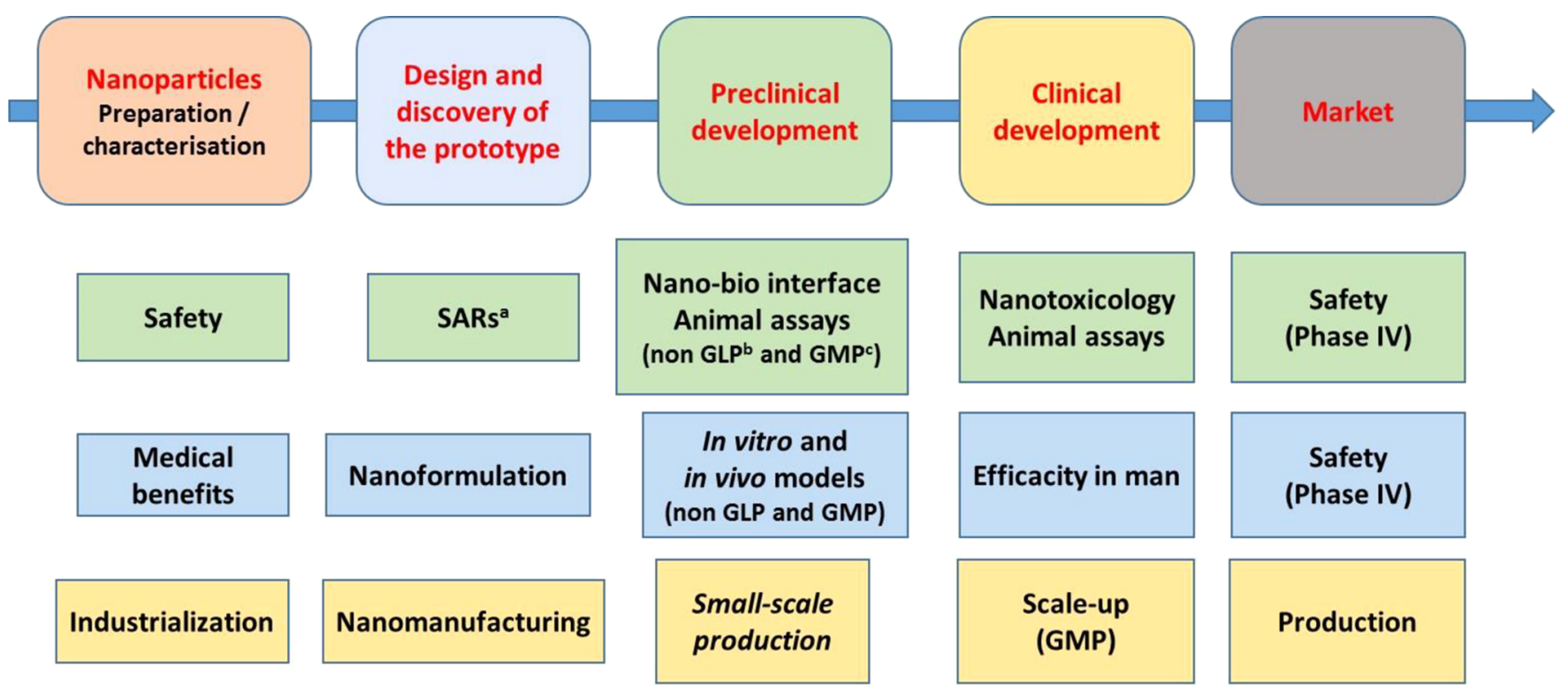

a Structure-activity-relationships b Good laboratory practices c Good manufacturing practices

Figure 3. Overview of critical paths to clinical applications of nanoparticles. Adapted from ref 91.

vivo biocompatibility of NPs in general and dendrimers in particular have been observed for cationic forms, having low hydrophilicity, and having a highly rigid core size, while high in vivo biocompatibility was observed for anionic species having high hydrophilicity and having a less rigid core. ${ }^{12}$ These features of nanoscale candidates, including dendrimers, required additional methods of characterization and new standards versus small compounds. ${ }^{76,73}$

Importantly, because NPs can interact with proteins with either beneficial or adverse effects, these issues need to be understood in-depth and are a major challenge of regulatory approval. ${ }^{27-29}$ Nanodrugs in general and dendrimers, in particular, have to go through very strict regulations and FDA/EMA guideline approval protocols before entering clinical trials and before marketing. Many of these translational requirements are also included in the "core" requirements for preclinical candidates to become clinical drug candidates.

Chemical space, outstandingly defined by Jean-Louis Reymond et al., ${ }^{77}$ has become a key concept in cheminformatics to evaluate the property space covered by all possible and meaningful chemical compounds including potential pharmacologically active molecules in drug discovery. This full examination is insuperable. On the basis of this important concept, we recently emphasized the development of the dendrimer space concept, which represents a key concept in nanomedicine drug discovery to find and develop new dendrimers in nanomedicine. ${ }^{78}$

Presently, dendrimers have emerged as versatile nanocarriers entrapping drugs, imaging agents, and targeting molecules. It is well-known that drugs entrapped within the cavities of NPs as supramolecular hosts have been found to improve the PK/PD profile of the drugs. ${ }^{72,79}$ In addition, the drugs of interest can be covalently conjugated with a cleavable linker, for instance, in tumors locations due to acidic $\mathrm{pH}$, or complexed on the surface of dendrimers, for instance, in the oncology domain. ${ }^{80}$ The design of tunable dendrimers as novel drug delivery systems, allowed NPs that (1) are capable of enhancing the effectiveness of the delivery of the drugs in the body by providing its gradual sustained release, and (2) are capable of interacting with specific targets. These targets were related to loaded drugs such as small/ large molecules, ${ }^{39}$ DNA (DNA-assembled dendrimer conjugates) targeting specific receptors, ${ }^{40}$ antibodies, ${ }^{81}$ as well molecules for specific recognition of tumor surfaces (e.g., folateconjugated dendrimers). ${ }^{82}$ Another critical point is the concept of enhanced permeability and retention (EPR) effects allowing the passive targeting of tumor cells in preference over healthy cells, increasing the effectiveness and the selective action. ${ }^{50,51}$ The EPR effect is based on the leaky vasculature of tumors with poorly aligned endothelial cells and large fenestrations. This may reduce the side effects of the drugs, which is important to improve in classical cancer chemotherapeutics. This effect has been recently questioned as a universal process in targeted therapy. As discussed by Cabrala and Kataoka ${ }^{22}$ and Ngoune et al., ${ }^{83}$ the heterogenicity of the vasculature and the permeability of tumors modify the perfusion and distribution of NPs within the tumor mass, and this effect could be rendered uneven. Also the use of dendrimers has increased the therapeutic index and decreased the drug resistance effects. An important point is that the design of dendrimers allows long-circulating times, reduces hemolytic toxicity, and reduces the release rate by introducing on the surface the "magic" PEGylated chains. ${ }^{84}$

Along the drug and therapy development continuum, three different stages can be identified: (1) early stage basic research: the advancement of knowledge (biology, chemistry, pharmacology, etc.) and the absence or low requirements to move to the clinical phases; (2) translational research: this stage is based on fundamental scientific knowledge, and the objective is to know how to move to clinical research with the maximum chance of success. This step includes the possible identification of biomarkers from patients, validation of the target based on the pharmacogenicity of the target which is related to the human disease, drug-related compounds or nanodrugs for drug delivery and therapeutics, adequate in vitro and in vivo activities, etc.; and (3) clinical research in humans to approve the safety of the treatment for patients. 


\section{REQUIREMENTS FROM PRECLINICAL TO MARKET}

Many of the nanodrugs are reviewed by regulatory agencies (FDA and EMA) as new features. Concerning dendrimers, the main basic requirement for dendrimers is to move toward an investigational new drug (IND) submission. According to the regulatory agencies' process, all NP submissions must demonstrate good disease-related margins of safety and high therapeutic efficacy to provide nanodevices that meet patient needs. For go/no-go decision-making during the development process, a list of the desired basic requirements to move toward an IND submission has recently been published. ${ }^{23,24,73}$ To this end, here we have outlined and fully analyzed the key parameters to be considered to secure the development of dendrimers for testing in clinical trials and to enhance their translation into the clinic. We recently proposed a simple set of guidelines based on several translational requirements to move toward an IND application, the first essential step to entering the clinical phase. $^{85}$

One of the crucial barriers to nanomedicine translation is to overcome challenges from the FDA by the evaluation of preclinical and clinical properties of each unknown component of the NPs. Nanodrugs in general and dendrimers, in particular, must go through very strict regulations and FDA/EMA guideline approval protocols before entering Phase I clinical trials after IND acceptance. In 2010, guidelines and reports were published by the FDA regarding important considerations to be taken into account about the evaluation of the nanoformulation properties of NPs including the following assessments: (1) pharmacokinetic profiles, (2) distribution to blood and tissues, (3) metabolism, (4) elimination, (5) accumulation in target tissues, and (6) toxicity. ${ }^{27-29,86,87,72,79,47}$ Recently, an interesting analysis has been highlighted by Bremer-Hoffmann et al. about the identification of challenges of regulatory needs for nanomedicine in nanomedicine. ${ }^{88}$

Collectively, Table 2 outlines the key requirements/milestones for NPs in general and dendrimers in particular as nanocarriers and as drugs from preclinical to market. These studies may or may not follow good laboratory practice (GLP) regulations as well as current good manufacturing practice (GMP) regulations, including the FDA and EMA residual solvent guidelines. Other nonclinical studies that are essential in human clinical trials should be planned, such as 3-6 months toxicology, reproductive toxicology (male fertility and pre- and postnatal development), chronic toxicology of at least 6 months, and carcinogenicity trials. Several FDA guidelines on the development of biocompatibility nanoparticles in clinical applications were highlighted. ${ }^{89,90}$ Figure 3 presents the critical paths to clinical applications of nanoparticles including dendrimers at a glance. ${ }^{91}$ Interestingly, very recently, an EMA criteria of nanosimilar drug products have been presented and analyzed by Fluhmann et al. ${ }^{92}$

As highlighted by Swenson, an important aspect is the "quality" of the synthesis of the dendrimers allowing "pure" macromolecules to enter in clinic. ${ }^{73}$ Two basic synthetic approaches were described based on divergent and convergent growth. The major drawbacks of the divergent approach are the incomplete conversion of the surface of dendrimers and the creation of defects, whereas the major drawback of convergent approach is the incomplete conjugation of dendrons to the core due to steric hindrance. The important purity aspect of dendrimers represents a challenge, and consequently every reaction needs to be very selective to ensure the integrity of the final product as noted by Bosman, Janssen, and Meijer. ${ }^{93}$ In the same review, the authors analyzed also other general aspects of dendrimers including molecular structure of dendrimers such as the position of end groups in dendrimers based on theoretical or experimental studies, extended arrangement for lower generation dendrimers versus a compact and approximate globular shape for higher generation dendrimers, and assembly profile of dendrimers. The characterization of dendrimers, for instance, for purity purposes, remains an important challenge due to the size of and symmetry in these macromolecules, for instance, in the development of dendrimers in medicinal chemistry.

Dendrimers have generated a large number of research publications, which have grown rapidly between 1996 and 2012, with a plateau between 2016 and 2018 (Scopus database). ${ }^{74}$ It should be noted that to date very few dendrimers are in clinical phase by systemic administration. An important question then arises as to why there are so many papers and so few NPs in general and dendrimers in particular based systemically administered drugs that have received regulatory approval. ${ }^{94}$ None of them are currently available on the market to treat diseases! Nevertheless, important progress has been made.

\section{CLINICAL SUCCESSES OF DENDRIMERS AS NANOCARRIERS OR DRUGS}

To date, few clinical successes have been reported using dendrimers as nanocarriers or drugs. For example, Roy and colleagues have developed dendritic glycopeptide mimotopes that are active on their own as cancer vaccine candidates. ${ }^{95}$ In 2012, Starpharma Holdings Limited (Melbourne, Australia) started two pivotal Phase III trials for the treatment of bacterial vaginosis with VivaGel (SPL7013 Gel, astodrimer sodium). This G4-poly(L-lysine) polyanionic dendron, which is active on its own, has 32 naphthalene disulfonate groups on its surface, which have shown to have potent topical vaginal microbicidal activity. VivaGel is available for sale (Betafem Gel) in the UK, and Starpharma has licensed the sales and marketing of VivaGel to ITF Pharma, Mundipharma, Aspen Pharmacare for the US, Europe/Russia/Asia/Africa/Latin America and Australia/New Zealand, respectively. In parallel, the antiviral condom VivaGel (VivaGel in lubricant) has also been licensed by Starpharma in several regions of the world. Starpharma/AstraZeneca has recently advanced from Phase I to Phase II with a poly(lysine) dendrimer-based nanocarrier encapsulating docetaxel (DEP docetaxel) showing superior anticancer activities against several important solid cancer types, including breast, prostate, lung, and ovarian tumors. Importantly, patients treated with DEP docetaxel showed no neutropenia side effects or life-threatening toxicity as seen in patients treated with conventional docetaxel formulations. In addition, Starpharma has other DEP products such as DEP cabazitaxel and DEP irinotecan in clinical development with AstraZeneca. ${ }^{96}$

Very interestingly, polyanionic carbosilane dendrimers have been developed by Angeles Muñoz-Fernández et al. from the Hospital General Universitario Gregorio (Spain) to fight HIV1. Researchers have been working for more than 20 years to develop safe and effective microbicides to empower women to better control their own sexual life and to protect themselves against HIV-1, as well as other sexually transmitted infections. The development of a safe and effective microbicide to prevent the HIV-1 sexual transmission is urgently needed. G2-S16 watersoluble anionic polyanionic carbosilane dendrimer has shown great potential as an antiviral agent in the development of a novel microbicide to prevent HIV-1 sexual transmission, blocking the 
gp120/CD4/CCR5 interaction, acting on the virus. ${ }^{97}$ It was demonstrated the dendrimer's capability to inhibit cell-to-cell HIV-1 transmission, confirming its multifactorial and nonspecific ability. It has also been shown that G2-S16 is active against mock- and semen-exposed HIV-1 being a promising microbicide against HIV-1 infection. ${ }^{98}$ No vaginal irritation was detected in $\mathrm{BALB} / \mathrm{c}$ mice and female rabbits after various consecutive applications for different times with $3 \%$ G2-S16. ${ }^{99}$ Daily treatment with G2-S16 either, by vaginal topical application or intravenous injection, does not modify the hemogram after 7 or 14 days of treatment. Interestingly enough, G2-S16 dendrimer does not interfere with the vaginal immune system. We showed that topical vaginal administration of $3 \%$ G2-S16 prevents HIV-1 transmission in humanized (h)-BLT mice in $84 \%$ with no presence of HIV-1 RNA and vaginal lesions. ${ }^{100}$ These findings provide a strong step forward in the development of G2-S16-based vaginal microbicides to prevent vaginal HIV-1 transmission in humans. These results have clearly shown that G2-S16 has high potency against HIV-1 transmission/infection.

\section{TRANSLATION ISSUES FROM RESEARCH TO THE CLINIC}

The majority of dendrimers as targeted nanocarriers have been used in cancer nanomedicine. The laboratory-to-clinic translation of NPs in general and dendrimers in particular remains a major challenge. All scientists (chemists, biologists, biomedical researchers, physicians, etc.) involved in nanomedicine using dendrimers must have a simple roadmap to interrupt the breakthrough from basic science to clinical applications named "bench-to-bedside". Thus, a disruptive innovation strategy should be used for the effective development of drugs up to the submission of an IND in the field of nanomedicine. The successful translation from research to the clinic should be achieved through the implementation of a simple roadmap to successfully jump the "valley of death". ${ }^{101}$ Collaboration with the pharmaceutical industry allows us to cross the "valley of death" between academic discoveries and clinical trials. This gap between the laboratory and the bedside is due to a lack of funding, incentives, and technical expertise. A recent interesting analysis of the clinical success rates showed the average of the probable success between 2010 and 2017 is Phase I to launch is $\sim 7 \%$, Phase II to launch is $\sim 13.5 \%$, Phase III to launch is $\sim 58 \%$, and Phase II to Phase III is $\sim 23 \%$. Cardiovascular and nervous system disorders are among the therapeutic areas showing the lowest probability of success (2010-2017). ${ }^{102}$

The key question is how academia and the pharmaceutical industry can best collaborate to cross the "valley of death" and solve clinical translation problems and what are the flagship initiatives to overcome these obstacles. The final objective is to develop NPs possessing a good balance between positive and negative attributes to develop practical drugs. Several roadmaps/processes have been proposed since 2003 such as (1) NIH (Zerhouni, 2003); ${ }^{103}$ (2) FDA Nanotechnology Task Force $(2007){ }^{104}$ (3) New York Academy of Sciences and Teva Pharmaceutical Industries $(2013) ;{ }^{105}(4)$ Morigi and colleagues $(2012) ;^{106}$ (5) Ehmann et al. (2013); ${ }^{107}$ (6) Eaton and colleagues (2015); ${ }^{108}$ and (7) Tyner et al. (2017). ${ }^{109}$

As highlighted by Korsmeyer, another crucial point to be analyzed is the complexity of NPs, which represents one of the major barriers for their design and development including manufacturing process. ${ }^{110}$ This point plays a crucial role in scaleup manufacture reproducibility for clinical use, and con- sequently, the biggest barrier to adoption by the pharmaceutical industry.

\section{CONCLUSIONS AND FUTURE PERSPECTIVES}

In the field of nanomedicine, a wide range of innovations is expected to affect this medical specialty and unveil new ways to improve quality and extend life. These gains can be measured at both the individual and population levels, for example, in treating severe diseases such as cancer and heart diseases. At the same time, the use of nanomedicine in public health applications, including rapid and portable diagnostics and more effective vaccinations, has revolutionized global healthcare.

Advances in nanomedicine will also have an impact on healthcare delivery systems to greatly improve safety and efficacy of therapy. Nanotechnology offers great potential for the development of new nanomedicines and delivery systems using nontoxic NPs, such as liposomes (also called solid lipid NPs), polymeric NPs, dendrimers, and metallic and inorganic NPs. Each type of NPs has specific properties and has been used to improve the therapeutic indices of incorporated drugs in a variety of ways, including bioavailability, retention time, protection of the trapped agent from the body's internal environment, and sustained release. Importantly, screening modalities with higher sensitivity and specificity for disease detection significantly improve prognosis and decrease healthcare costs. As highlighted and analyzed by Bosetti, ${ }^{111}$ based on the great potential of the nanomedical market, the costeffectiveness of nanomedicine combines two important aspects: (1) bring excellent healthcare solutions, and (2) efficient commercialization of nanotechnology-based therapeutics.

It should be noted that, in general, these new technologies are often more expensive than traditional medical treatments, and therefore, to be developed, they must be much more effective than these. This challenge will be overcome with sufficient data to clearly demonstrate the benefits of new applications of nanomedicine in the prevention, diagnosis, and treatment of diseases relative to standards. ${ }^{100}$ These aspects have been anticipated as the revolutionized treatments and diagnostics named "nanomedicine revolution".

On the basis of the concept of "dendrimer space", recently defined by us ${ }^{78}$ which opens up a new paradigm for medicinal chemists and promising new avenues through the identification of novel dendrimer-based drugs, the development of dendrimers undoubtedly represents new opportunities in nanomedicine to treat patients. The most important challenge is to select the right (biocompatible) dendrimers. In this perspective paper, we have analyzed the current situation and proposed guidelines for moving from the discovery stage to commercialization through clinical trials, both for dendrimers as nanocarriers and as drugs. As several scientists such as Venditto and Szoka ${ }^{94}$ have mentioned, in the field of nanomedicine, there are many papers and very few drugs. Therefore, a key question remains of how academia and the pharmaceutical industry can best collaborate to cross the "valley of death" to solve the problem of clinical translation of NPs in general and dendrimers in particular. An additional question is what the flagship initiatives are to overcome these obstacles and to find trade-offs between several physical and therapeutic aspects to develop new multifunctional nanomedicines.

In this regard, an appealing and versatile approach has been recently disclosed that may revolutionize the design of classical dendrimers that are essentially based on using the same building 
blocks at each generation layers. ${ }^{112}$ This was nicely accomplished using two variables. The first one consists in using a highly functionalized core similar to the one developed by the Majoral's group (ex. AB5) as opposed to the traditional AB2 cores used for PAMAM and PEI. In this way, larger numbers of surface group functionalities can be accomplished in much fewer generations. Second, by varying the chemical entities at each layer (ex. AB2, $A B 3, A B 4)$, it becomes easier to modulate/adjust the physico-(bio)chemical properties of the newly created dendrimers to fit the intended applications of the nanomaterials.

We are convinced that the inclusion of public health professionals/experts working with researchers from industry is essential and can play a key role in addressing this issue by developing research and development strategies to transparently disseminate information about the risks, costs, and therapeutic benefits of innovative NPs, including dendrimers, in order to maximize individual and population health gains.

We are also convinced that the best way to develop nanomedicines consist of collecting and sharing information from academia and industry and set up a common process based on a useful and straightforward algorithm, like that suggested by Choi and colleagues, ${ }^{23}$ providing practical checkpoints in nanomedicine development.

It is important to note that expanding the interdisciplinary and collaborative approach to nanomedicine research and education, such as the training of researchers, medical care providers, and public health professionals working in the industry, government, and academia, will provide an excellent opportunity to develop innovative NPs. In addition, this strategy will effectively advance the state of nanoscience, which will also result in a better return on public health investments. In addition, these collaborations based on this "open innovation strategy" will help to make the best use of funds allocated by governments and industries. The improvement of this collaboration will allow better patient selection for future NPs-based therapeutics. In this direction, note that, interestingly, a DNA-based multiplexing technology for rapid and accurate diagnosis of pathogens (respiratory diseases, sexual diseases, for example) was developed using phosphorus dendrimers by Majoral et al. ${ }^{53}$

In conclusion, use of dendrimers as a cargo of drugs and/or as drugs active per se which was considered as a utopia a few years ago, slowly but inexorably represents a real alternative and a support force to solve many aspects of human health, thanks to the contribution of many research groups worldwide keeping in mind the possibility to avoid numerous side effects and poor activity of many drugs. We are also convinced as suggested by Guidolin and Zhen that we need to change the design philosophy of nanomedicines in general and dendrimers in particular. ${ }^{113}$ This strategy will help plug the gap between basic science and clinical development of dendrimers during the translation process. Even if we consider that the field of NPs is very active, the scientific community must convince the biopharmaceutical industries that NPs can become the better medicines of the 21 st century. Nevertheless, a question remains: practically, how can ideal nanodrugs be defined in terms of pharmaceutical industry standards? The field of nanomedicine has made outstanding strides in the domain of therapeutic and diagnostic development and will be further amplified through the use of artificial intelligence to improve treatment outcomes as highlighted recently by $\mathrm{Ho}$ and colleagues. ${ }^{114}$ Another important point to be addressed in nanomedicine in general and dendrimer in particular is the study of the interactions between dendrimers and the immune system during the clinical phases as highlighted by La-Beck and Gabizon for liposome-based cancer chemotherapy. ${ }^{115}$

\section{AUTHOR INFORMATION}

\section{Corresponding Authors}

Serge Mignani - Université Paris Descartes, PRES Sorbonne Paris Cite, CNRS UMR 860, Laboratoire de Chimie et de Biochimie Pharmacologiques et Toxicologique, 75006 Paris, France; CQM Centro de Química da Madeira, MMRG, Universidade da Madeira, 9020-105 Funchal, Portugal; Glycovax Pharma, Montreal, Quebec, Canada H3J 1S6; Email: serge.mignani@ parisdescartes.fr

Xiangyang Shi - CQM - Centro de Química da Madeira, MMRG, Universidade da Madeira, 9020-105 Funchal, Portugal; State Key Laboratory for Modification of Chemical Fibers and Polymer Materials, College of Chemistry, Chemical Engineering and Biotechnology, Donghua University, Shanghai 201620, PR China; 이이.org/0000-0001-6785-6645;Email: xshi@ dhu.edu.cn

Jean-Pierre Majoral - Laboratoire de Chimie de Coordination $d u$ CNRS, 31077 Toulouse, Cedex 4, France; Universite Toulouse, 31077 Toulouse, Cedex 4, France; 이 orcid.org/0000-00020971-817X; Email: jean-pierre.majoral@lcc-toulouse.fr

\section{Authors}

João Rodrigues - CQM - Centro de Química da Madeira, MMRG, Universidade da Madeira, 9020-105 Funchal, Portugal; School of Materials Science and Engineering/Center for Nano Energy Materials, Northwestern Polytechnical University, Xi'an 710072, PR China; 이이이.org/0000-0003-4552-1953

René Roy - Glycovax Pharma, Montreal, Quebec, Canada H3J 1S6; (1) orcid.org/0000-0001-5638-7302

Ángeles Muñoz-Fernández - Sección Inmunología, Laboratorio InmunoBiología Molecular, Hospital General Universitario Gregorio Marañon, Madrid, Spain, Instituto de Investigación Sanitaria Gregorio Marañón (IiSGM), Madrid, Spain, Spanish HIV HGM BioBank, Madrid, Spain, Networking Research Center on Bioengineering, Biomaterials and Nanomedicine (CIBER-BBN), Madrid, Spain; ำ orcid.org/0000-0002-08134500

Valentin Ceña - CIBERNED, ISCII, Madrid; Unidad Asociada Neurodeath, Universidad de Castilla-La Mancha, 02006

Albacete, Spain; 이이. orcid.org/0000-0001-8928-3681

Complete contact information is available at:

https://pubs.acs.org/10.1021/acs.bioconjchem.0c00395

\section{Notes}

The authors declare no competing financial interest.

\section{ACKNOWLEDGMENTS}

X.S., S.M., and J.-P.M. thank the PRC NSFC-CNRS 2019 (21911530230 for X.S. and 199675 for S.M. and J-P.M). J.R., S.M., and X.S. acknowledge the support of FCT-Fundação para a Ciência e a Tecnologia (Base Fund UIDB/00674/2020 and Programmatic Fund UIDP/00674/2020, Portuguese Government Funds) and ARDITI-Agência Regional para o Desenvolvimento da Investigação Tecnologia e Inovação through Project M1420-01- 0145-FEDER-000005-CQM+ (Madeira 14-20 Program). S.M., V.C., R.R., and J.-P.M. acknowledge transnational EuroNanoMed III funded projects including a proper acknowledgement of ERANET EuroNanoMed III and the respective funding partner organizations. V.C. acknowledges the support of the Spanish Ministerio de Economia y Compet- 
itividad (Project SAF2017-89288-R from MINECO/AEI/ FEDER/UE) and JCCM (Project SBPLY/19/180501/ 000067). M.A.M.-F. acknowledges the support of RD16/ 0025/0019 and PI16/01863 projects as part of the Acción Estratégica en Salud, Plan Nacional de Investigación Cientifica, Desarrollo e Innovación Tecnológica by ISCIII, Fondos FEDER and CIBER BBN. The RIS Cohort (CoRIS) is funded by the ISCIII through the Spanish AIDS Research Network (RIS C03/ 173 and RD12/0017/0018) Action. COST Action Ca 17140 and NAW European Project. J.P.M. thanks CNRS (France) for financial support.

\section{REFERENCES}

(1) Cummins, R. A. (2015) Understanding quality of life in medicine: a new approach. J. Am. Coll. Nutr. 34, 4-9.

(2) Grand View Research (2020) https://www.grandviewresearch. com/press-release/global-nanomedicine-market.

(3) National Cancer Institute (2020) Precision Medicine in Cancer Treatment. https://www.cancer.gov/about-cancer/treatment/types/ precision-medicine.

(4) Feynman, R. P. (1960) There's plenty of room at the bottom. Eng. Sci., 22-36.

(5) Salvioni, L., Rizzuto, M. A., Bertolini, J. A., Pandolfi, L., Colombo, M., and Prosperi, D. (2019) Thirty Years of Cancer Nanomedicine: Success, Frustration, and Hope. Cancers 11, 1855.

(6) Giménez, V. M. M., Kassuha, D. E., and Manucha, W. (2017) Nanomedicine applied to cardiovascular diseases: latest developments. Ther. Adv. Cardiovasc. Dis. 11, 133-142.

(7) Soni, S., Ruhela, R. K., and Medhi, B. (2016) Nanomedicine in central nervous system (CNS) disorders: A present and future prospective. Adv. Pharm. Bull. 6 (6), 319-335.

(8) Tuntland, T., Ethell, B., Kosaka, T., Blasco, F., Zang, R. X., Jain, M., Gould, T., and Hoffmaster, K. (2014) Implementation of pharmacokinetic and pharmacodynamic strategies in early research phases of drug discovery and development at Novartis Institute of Biomedical Research. Front. Pharmacol. 5, 174.

(9) Su, C., Liu, Y., Li, R., Wu, W., Fawcett, J. P., and Gu, J. (2019) Absorption, distribution, metabolism and excretion of the biomaterials used in Nanocarrier drug delivery systems. Adv. Drug Delivery Rev. 143, 97-114.

(10) Hinchcliffe, M., and Smith, A. (2017) Riluzole: real-world evidence supports significant extension of median survival times in patients with amyotrophic lateral sclerosis. Degener. Neurol. Neuromuscular Dis. 7, 61-70.

(11) Ionov, M., Gardikis, K., Wróbel, D., Hatziantoniou, S., Mourelatou, H., Majoral, J.-P., Klajnert, B., Bryszewska, M., and Demetzos, C. (2011) Interaction of cationic phosphorus dendrimers (CPD) with charged and neutral lipid membranes. Colloids Surf., B 82, $8-12$.

(12) Khandare, J., Calderon, M., Dagia, N. M., and Haag, R. (2012) Multifunctional dendritic polymers in nanomedicine: opportunities and challenges. Chem. Soc. Rev. 41, 2824-2848.

(13) Blanco, E., Shen, H., and Ferrari, M. (2015) Principles of nanoparticle design for overcoming biologi-cal barriers to drug delivery. Nat. Biotechnol. 33, 941-951.

(14) Fornaguera, C., and Garcia-Celma, M. J. (2017) Personalized nanomedicine: A revolution at the nanoscale. J. Pers. Med. 7, 12.

(15) Langbein, T., Weber, W. A., and Eiber, M. (2019) Future of Theranostics: An Outlook on Precision Oncology in Nuclear Medicine. J. Nucl. Med. 60, 13S-19S.

(16) Rajagopalan, R., and Yakhmi, J. V. (2017) In Nanostructures for Cancer Therapy, pp 211-240, Chapter 8 - Nanotechnological approaches toward cancer chemotherapy, Micro and Nano Technologies.

(17) Weiss, C., Carriere, M., Fusco, L., Capua, I., Regla-Nava, J. A., Pasquali, M., Scott, J. A., Vitale, F., Unal, M. A., Mattevi, C., Bedognetti, D., Merkoçi, A., Tasciotti, E., Yilmazer, A., Gogotsi, Y., Stellacci, F., and
Delogu, L. G. (2020) Toward Nanotechnology-Enabled Approaches against the COVID-19 Pandemic. ACS Nano 14, 6383-6406.

(18) Fahmy, T. M., Fong, P. M., Goyal, A., and Saltzman, W. M. (2005) Targeted for drug delivery. Mater. Today 8, 18-26.

(19) Chan, J. M., Valencia, P. M., Zhang, L., Langer, R., and Farokhzad, O. C. (2010) Polymeric Nanoparticles for Drug Delivery. Methods Mol. Biol. 624, 163-175.

(20) Seo, S. E., and Hawker, C. J. (2020) The Beauty of Branching in Polymer Science. Macromolecules 53, 3257-3261.

(21) Bulbake, U., Doppalapudi, S., Kommineni, N., and Khan, W. (2017) Liposomal formulations in clinical use: An updated review. Pharmaceutics 9, 12.

(22) Cabral, H., and Kataoka, K. (2014) Progress of drug-loaded polymeric micelles into clinical studies. J. Controlled Release 190, 465476.

(23) Choi, Y. H., and Han, H. K. (2018) Nanomedicines: Current Status and Future Perspectives in Aspect of Drug Delivery and Pharmacokinetics. J. Pharm. Invest. 48, 43-60.

(24) Fluhmann, B., Ntai, I., Borchard, G., Simoens, S., and Muhlebach, S. (2019) Nanomedicines: The Magic Bullets Reaching Their Target? Eur. J. Pharm. Sci. 128, 73-80.

(25) Farjadian, F., Ghasemi, A., Gohari, O., Roointan, A., Karimi, M., and Hamblin, M. R. (2019) Nanopharmaceuticals and nanomedicines currently on the market: challenges and oppor-tunities. Nanomedicine $14,93-126$.

(26) Sercombe, L., Veerati, T., Moheimani, F., Wu, S. Y., Sood, A. K., and Hua, S. (2015) Advances and Challenges of Liposome Assisted Drug Delivery. Front. Pharmacol. 6, 286.

(27) Bobo, D., Robinson, K. J., Islam, J., Thurecht, K. J., and Corrie, S. R. (2016) Nanoparticle-based medicines: A review of FDA-approved materials and clinical trials to date. Pharm. Res. 33, 2373-2387.

(28) Drug Products, Including Biological Products, that Contain Nanomaterials Guidance for Industry, https://www.fda.gov/files/ drugs/published/Drug-Products--Including-Biological-Products--thatContain-Nanomaterials---Guidance-for-Industry.pdf.

(29) Nanotechnology, https://www.fda.gov/regulatory-information/ search-fda-guidance-documents/considering-whether-fda-regulatedproduct-involves-application-nanotechnology.

(30) Felder-Flesch, D. (2016) Dendrimers in Nanomedicine, Jenny Stanford Publishing.

(31) Sun, T., Zhang, Y. S., Pang, B., Hyun, D. C., Yang, M., and Xia, Y. (2014) Engineered Nanoparticles for Drug Delivery in Cancer Therapy. Angew. Chem., Int. Ed. 53, 12320-12364.

(32) Kesharwani, P., Jain, K., and Jain, N. K. (2014) Dendrimer as nanocarrier for drug delivery. Prog. Polym. Sci. 39, 268-307.

(33) McCarthy, T. D., Karellas, P., Henderson, S. A., Giannis, M., O'Keefe, D. F., Heery, G., Paull, J. R. A., Matthews, B. R., and Holan, G. (2005) Dendrimers as Drugs: Discovery and Preclinical and Clinical Development of Dendrimer-Based Microbicides for HIV and STI Prevention. Mol. Pharmaceutics 2, 312-318.

(34) Vinicius de Araújo, R., da Silva Santos, S., Ferreira, E. I., and Giarolla, J. (2018) New advances in general biomedical applications of PAMAM dendrimers. Molecules 23, 2849.

(35) Zhong, D., Wu, H., Wu, Y., Li, Y., Xu, X., Yang, J., and Gu, Z. (2019) Rational design and facile fabrication of biocompatible triple responsive dendrimeric nanocages for targeted drug delivery. Nanoscale 11, 15091-15103.

(36) Mignani, S., El Kazzouli, S., Bousmina, M., and Majoral, J.-P. (2013) Expand classical drug admin-istration ways by emerging routes using dendrimer drug delivery systems: A Concise overview. Adv. Drug Delivery Rev. 65, 1316-1330.

(37) Kannan, R. M., Nance, E., Kannan, S., and Tomalia, D. A. (2014) Emerging concepts in dendrimer-based nanomedicine: from design principles to clinical applications. J. Intern. Med. 276, 579-617.

(38) Kaminskas, L. M., Boyd, B. J., and Porter, C. J. H. (2011) Dendrimer pharmacokinetics: the effect of size, structure and surface characteristics on ADME properties. Nanomedicine 6, 1063-1084.

(39) Kesharwani, P., Jain, K., and Jain, N. K. (2014) Dendrimer as nanocarrier for drug delivery. Prog. Polym. Sci. 39, 268-307. 
(40) Dufès, C., Uchegbu, I. F., and Schätzlein, A. G. (2005) Dendrimers in Gene Delivery. Adv. Drug Delivery Rev. 57, 2177-2202. (41) Palmerston Mendes, L., Pan, J., and Torchilin, V. (2017) Dendrimers as nanocarriers for nucleic acid and drug delivery in cancer therapy. Molecules 22, 1401.

(42) Mignani, S., Shi, X., Zablocka, M., and Majoral, J.-P. (2019) Dendrimer-enabled therapeutic antisense delivery systems as innovation in medicine. Bioconjugate Chem. 30, 1938-1950.

(43) Liu, X., Huang, H., Wang, J., Wang, C., Wang, M., Zhang, B., and Pan, C. (2011) Dendrimers-delivered short hairpin RNA targeting hTERT inhibits oral cancer cell growth in vitro and in vivo. Biochem. Pharmacol. 82, 17-23.

(44) Biswas, S., and Torchilin, V. P. (2013) Dendrimers for siRNA delivery. Pharmaceuticals 6, 161-183.

(45) Madaan, K., Kumar, S., Poonia, N., Lather, V., and Pandita, D. (2014) Dendrimers in drug delivery and targeting: drug-dendrimer interactions and toxicity issues. J. Pharm. BioAllied Sci. 6, 139-150.

(46) Mignani, S., Shi, X., Ceña, V., and Majoral, J.-P. (2020) Dendrimer-and polymeric nanoparticle-aptamer bioconjugates as nonviral delivery systems: a new approach in medicine. Drug Discovery Today 25, 1065-1073.

(47) Tomalia, D. A., Nixon, L. S., and Hedstrand, D. M. (2020) The Role of Branch Cell Symmetry and Other Critical Nanoscale Design Parameters in the Determination of Dendrimer Encapsulation Properties. Biomolecules 10, 642.

(48) Santos, A., Veiga, F., and Figueiras, A. (2020) Dendrimers as pharmaceutical excipients: Synthesis, properties, toxicity and biomedical applications. Materials 13, 65.

(49) Wu, L.-P., Ficker, M., Christensen, J. B., Trohopoulos, P. N., and Moghimi, S. M. (2015) Dendrimers in medicine: therapeutic concepts and pharmaceutical challenges. Bioconjugate Chem. 26, 1198-1211.

(50) Zhang, B., Hu, Y., and Pang, Z. (2017) Modulating the tumor microenvironment to enhance tumor nanomedicine delivery. Front. Pharmacol. 8, 952.

(51) Danhier, F. (2016) Exploit the Tumor Microenvironment: Since the EPR Effect Fails in the Clinic, What Is the Future of Nanomedicine? J. Controlled Release 244, 108-121.

(52) Ghaffari, M., Dehghan, G., Abedi-Gaballu, F., Kashanian, S., Baradaran, B., Dolatabadi, J. E. N., and Losic, D. (2018) Surface functionalized dendrimers as controlled-release delivery nanosystems for tumor targeting. Eur. J. Pharm. Sci. 122, 311-330.

(53) Caminade, A.-M., Turrin, O., and Majoral, J.-P., Eds. (2018) Phosphorus Dendrimers in Biology and Nanomedicine, Pan Stanford Publishing.

(54) Chen, L., Li, J., Fan, Y., Qiu, J., Cao, L., Laurent, R., Mignani, S., Caminade, A.-M., Majoral, J.-P., and Shi, X. (2020) Revisiting cationic phosphorus dendrimers as a nonviral vector for optimized gene delivery toward cancer therapy applications. Biomacromolecules 21, 2502-2511.

(55) Hayder, M., Poupot, M., Baron, M., Nigon, D., Turrin, C. O., Caminade, A. M., Majoral, J.-P., Eisenberg, R. A., Fournié, J. J., Cantagrel, A., Poupot, R., and J-L, D. (2011) A phosphorus-based dendrimer targets inflammation and osteoclastogenesis in experimental arthritis. Sci. Transl. Med. 3, 81ra35.

(56) Bohr, A., Tsapis, N., Andreana, I., Chamarat, A., Foged, C., Delomenie, C., Noiray, M., El Brahmi, N., Majoral, J.-P., Mignani, S., and Fattal, E. (2017) Anti-Inflammatory effect of anti-TNF-SiRNA cationicphosphorus dendrimer nanocomplexes administeredintranasally in a murine acute lung injury model. Biomacromolecules 18, 23792388.

(57) Mignani, S., and Majoral, J.-P. (2013) Dendrimers as macromolecular tools to tackle from colon to brain tumor types: a concise overview. New J. Chem. 37, 3337-3357.

(58) Serri, A., Mahboubi, A., Zarghi, A., and Moghimi, H. R. (2018) PAMAM-dendrimer enhanced antibacterial effect of vancomycin hydrochloride against Gram-Negative bacteria. J. Pharm. Pharm. Sci. $22,10-21$.

(59) Holmes, A. M., Heylings, J. R., Wan, K. W., and Moss, G. P. (2019) Antimicrobial efficacy and mechanism of action of poly- (amidoamine) (PAMAM) dendrimers against opportunistic pathogens. Int. J. Antimicrob. Agents 53, 500-507.

(60) Sharma, A., Porterfield, J. E., Smith, E., Sharma, R., Kannan, S., and Kannan, R. M. (2018) Effect of mannose targeting of hydroxyl PAMAM dendrimers on cellular and organ biodistribution in a neonatal brain injury model. J. Controlled Release 283, 175-189.

(61) Shukla, R., Thomas, T. P., Peters, J., Kotlyar, A., Myc, A., and Baker, J. R., Jr. (2005) Tumor angiogenic vasculature targeting with PAMAM dendrimer-RGD conjugates. Chem. Commun., 5739.

(62) Wang, B., Navath, R. S., Menjoge, A. R., Balakrishnan, B., Bellair, R., Dai, H., Romero, R., Kannan, S., and Kannan, R. M. (2010) Inhibition of bacterial growth and intramniotic infection in a guinea pig model of chorioamnioitis using PAMAM dendrimers. Int. J. Pharm. 395, 298-308.

(63) Milowska, K., Grochowina, J., Katir, N., El Kadib, A., Majoral, J.P., Bryszewska, M., and Gabryelak, T. (2013) Viologen-phosphorus dendrimers inhibit $\alpha$-synuclein fibrillation. Mol. Pharmaceutics 10, $1131-1137$.

(64) Maciel, D., Guerrero-Beltrán, C., Ceña-Diez, R., Tomás, H., Muñoz-Fernández, M., and Rodrigues, J. M. (2019) New anionic poly(alkylideneamine) dendrimers as microbicide agents against HIV-1 infection. Nanoscale 11, 9679-9690.

(65) Solassol, J., Crozet, C., Perrier, V., Leclaire, J., Beranger, F., Caminade, A. M., Meunier, B., Dormont, D., Majoral, J.-P., and Lehmann, S. (2004) Cationic phosphorus-containing dendrimers reduce prion replication both in cell culture and in mice infected with scrapie. J. Gen. Virol. 85, 1791-1799.

(66) Chen, L., Mignani, S., Caminade, A. M., and Majoral, J.-P. (2019) Metal-based phosphorus dendrimers as novel nanotherapeutic strategies to tackle cancers: A concise overview. Wiley Interdiscip. Rev.: Nanomed. Nanobiotechnol. 11, 11.

(67) Holota, H., Magiera, J., Michlewska, S., Kubczak, M., Sanz del Olmo, N., Garcia-Gallego, S., Ortega, P., Javier de la Mata, F., Ionov, M., and Bryszewska, M. (2019) In vitro anti-cancer properties of copper metallodendrimers. Biomolecules 9, 155.

(68) Gouveia, M., Figueira, J., Jardim, M. G., Castro, R., Tomas, H., Rissanen, K., and Rodrigues, J. (2018) Poly(alkylidenimine) Dendrimers Functionalized With the Organometallic Moiety $\left[\mathrm{Ru}\left(\eta^{5}\right.\right.$ $\left.\left.\mathrm{C}_{5} \mathrm{H}_{5}\right)\left(\mathrm{PPh}_{3}\right)_{2}\right]^{+}$as Promising Drugs Against Cisplatin-Resistant Cancer Cells and Human Mesenchymal Stem Cells. Molecules 23, 1471.

(69) Chabre, Y. M., and Roy, R. (2010) Design and creativity in synthesis of multivalent neoglycoconjugates. Ed. D. Horton 63, 165393.

(70) Chabre, Y. M., and Roy, R. (2013) Multivalent glycoconjugate syntheses and applications using aromatic scaffolds. Chem. Soc. Rev. 42, 4657-4708.

(71) Mignani, S., Rodrigues, J., Roy, R., Shi, X., Ceña, V., El Kazzouli, S., and Majoral, J.-P. (2019) xplo-ration of biomedical dendrimer space based on in-vitro physicochemical parameters: key factor analysis (Part 1). Drug Discovery Today 24, 1176-1183.

(72) Mignani, S., Rodrigues, J., Roy, R., Shi, X., Ceña, V., El Kazzouli, S., and Majoral, J.-P. (2019) Exploration of biomedical dendrimer space based on in-vivo physicochemical parameters: key factor analysis (Part 2). Drug Discovery Today 24, 1184-1192.

(73) Swenson, S. (2015) The dendrimer paradox -high medical expectations but poor clinical translation. Chem. Soc. Rev. 44, 41314144.

(74) Janaszewska, A., Lazniewska, J., Trzepiński, P., Marcinkowska, M., and Klajnert-Maculewicz, B. (2019) Cytotoxicity of dendrimers. Biomolecules 9, 330 .

(75) Kannan, R. M., Nance, E., Kannan, S., and Tomalia, D. A. (2014) Emerging concepts in dendrimer-based nanomedicine: from design principles to clinical applications. J. Intern. Med. 276, 579-617.

(76) Mourdikoudis, S., Pallares, R. M., and Thanh, N. T. K. (2018) Characterization techniques for nano-particles: comparison and complementarity upon studying nanoparticle properties. Nanoscale $10,12871-12934$. 
(77) Reymond, J.-L., van Deursen, R., Blum, L. C., and Ruddigkeit, L. (2010) Chemical space as a source for new drugs. MedChemComm 1, $30-38$.

(78) Mignani, S., El Kazzouli, S., Bousmina, M. M., and Majorale, J.-P. (2013) Dendrimer space concept for innovative nanomedicine: a futuristic vision for medicinal chemistry. Prog. Polym. Sci. 38, 9931008.

(79) Cheng, Y., and Xu, T. (2008) The effect of dendrimers on the pharmacodynamic and pharmacoki-netic behaviors of non-covalently or covalently attached drugs. Eur. J. Med. Chem. 43, 2291-2297.

(80) Mignani, S., Rodrigues, J., Tomas, H., Zablocka, M., Shi, X., Caminade, A. M., and Majoral, J.-P. (2018) Dendrimers in combination with natural products and analogues as anti-cancer agents. Chem. Soc. Rev. 47, 514-532.

(81) Wängler, C., Moldenhauer, G., Eisenhut, M., Haberkorn, U., and Mier, W. (2008) Antibody-dendrimer conjugates: The number, not the size of the sendrimers, setermines the immu-noreactivity. Bioconjugate Chem. 19, 813-820.

(82) van Dongen, M. A., Silpe, J. E., Dougherty, C. A., Kanduluru, A. K., Choi, S. K., Orr, B. G., Low, P. S., and Banaszak Holl, M. M. (2014) Avidity mechanism of dendrimer-folic acid conjugates. Mol. Pharmaceutics 11, 1696-1706.

(83) Ngoune, R., Peters, A., von Elverfeldt, D., Winkler, K., and Putz, G. (2016) Accumulating nanoparticles by EPR: A route of no return. J. Controlled Release 238, 58-70.

(84) Chauban, A., and Kulhari, H., Eds. (2020) Pharmaceutical Applications of Dendrimers; Elsevier.

(85) Mignani, S., Rodrigues, J., Tomas, H., Roy, R., Shi, X., and Majoral, J.-P. (2018) Bench-to-bedside translation of dendrimers: reality or utopia? A concise analysis. Adv. Drug Delivery Rev. 136, 7381.

(86) Peña, C. A FDA Perspective on Nanomedicine Current Initiatives in the US. https://www.ema.europa.eu/en/documents/ presentation/presentation-nanomedicines-current-initiatives-uscarlos-pea-fda_en.pdf.

(87) Jones, A.-A. D., Mi, G., and Webster, T. J. (2019) A status report on FDA approval of medical devices containing nanostructured materials. Trends Biotechnol. 37, 117-120.

(88) Bremer-Hoffmann, S., Halamoda-Kenzaoui, B., and Borgos, S. E. (2018) Identification of regulatory needs for nanomedicines. Journal of Interdisciplinary Nanomedicine 3, 4-15.

(89) Use of International Standard ISO 10993-1, "Biological evaluation of medical devices - Part 1: Evaluation and testing within a risk management process" (2016) https://www.fda.gov/media/ 85865 /download .

(90) Nanotechnology Guidance Documents. (1997) https://www. $\mathrm{fda} \cdot \mathrm{gov} / \mathrm{science-research/nanotechnology-programs-fda/}$ nanotechnology-guidance-documents.

(91) Webster, T. J., Ed. (2009) Safety of Nanoparticles: From Manufacturing to Medical Applications, Nanostructure Science and Technology (Lockwood, D. J., Series Ed.) Springer.

(92) Fluhmann, B., Ntai, I., Borchard, G., Simoens, S., and Muhlebach, S. (2019) Nanomedicines: The amjic bullets reaching their target? Eur. J. Pharm. Sci. 128, 73-80.

(93) Bosman, A. W., Janssen, H. M., and Meijer, E. W. (1999) About Dendrimers: Structure, Physical Properties, and Applications. Chem. Rev. 99, 1665-1688.

(94) Venditto, V. J., and Szoka, F. C. (2013) Cancer nanomedicines: So many papers and so few drugs! Adv. Drug Delivery Rev. 65, 80-88.

(95) Heimburg-Molinaro, J., Almogren, A., Morey, S., Glinskii, O. V., Roy, R., Wilding, G. E., Cheng, R. P., Glinsky, V. V., and RittenhouseOlson, K. (2009) Development, characterization, and immunotherapeutic use of peptide mimics of the Thomsen-Friedenreich carbohydrate antigen. Neoplasia 11, 780-792.

(96) https://starpharma.com/about_us

(97) Munoz-Fernandez, M. A., Cena Diez, R., Garcia Broncano, P., de la Mata, F. J., and Gomez, R. (2016) Efficacy of HIV antiviral polyanionic carbosilane dendrimer G2-S16 in the presence of semen. Int. J. Nanomed. 11, 2443-2450.
(98) Chonco, L., Pion, M., Vacas, E., Rasines, B., Maly, M., Serramia, M. J., Lopez-Fernandez, L., De la Mata, J., Alvarez, S., Gomez, R., and Munoz-Fernandez, M. A. J. (2012) Carbosilane dendrimer nanotechnology outlines of the broad HIV blocker profile. J. Controlled Release 161, 949-958.

(99) Martin-Moreno, A., Sepulveda-Crespo, D., Serramia-Lobera, M., Perise-Barrios, A. J., and Ange les Munoz-Fernandez, M. A. (2019) G2S16 dendrimer microbicide does not interfere with the vaginal immune system. J. Nanobiotechnol. 17, 65.

(100) Sepulveda-Crespo, D., Serramia, M. J., Tager, A. M., Vrbanac, V., Gomez, R., Javier De la Mata, F., Jimenez, J. L., and MunozFernandez, M. A. (2015) Prevention vaginally of HIV-1 transmission in humanized BLT mice and mode of antiviral action of polyanionic carbosilane dendrimer G2-S16. Nanomedicine 11, 1299-1308.

(101) Parrish, M. C., Tan, Y. J., Grimes, K. V., and Mochly-Rosen, D. (2019) Surviving in the Valley of Death: Opportunities and Challenges in Translating Academic Drug Discoveries. Annu. Rev. Pharmacol. Toxicol. 59, 405-421.

(102) Dowden, H., and Munro, J. (2019) Trends in Clinical Success Rates and Therapeutic Focus. Nat. Rev. Drug Discovery 18, 495-496.

(103) Zerhouni, E. (2003) Medicine. The NIH roadmap. Science 302, 63-72.

(104) Nanotechnology Task Force Report 2007 (2007) https://www. fda.gov/science-research/nanotechnology-programs-fda/ nanotechnology-task-force-report-2007\#mission. .

(105) Tinkle, S., McNeil, S. E., Muehlebach, S., Bawa, R., Borchard, G., Barenholz, Y., Tamarkin, L., and Desai, N. (2014) Nanomedicines: addressing the scientific and regulatory gap. Ann. N. Y. Acad. Sci. 1313, 35-56.

(106) Morigi, V., Tocchio, A., Bellavite Pellegrini, C., Sakamoto, J. H., Arnone, M., and Tasciotti, E. (2012) Nanotechnology in medicine: From inception to market domination. J. Drug Delivery 2012, 389485389485.

(107) Ehmann, F., Sakai-Kato, K., Duncan, R., de la Ossa, D. H. P., Pita, R., Vidal, J. M., Kohli, A., Tothfalusi, L., Sanh, A., Tinton, S., Robert, J. L., Lima, B. S., and Amati, M. P. (2013) Next generation nanomedicines and nanosimilars: EU regulators' initiatives relat-ing to the development and evaluation of nanomedicines. Nanomedicine 8, 849-856.

(108) Eaton, M. A. W., Levy, L., and Fontaine, O. M. A. (2015) Delivering nanomedicines to patients: A practical guide. Nanomedicine 11, 983-992.

(109) D’Mello, S. R., Cruz, C. N., Chen, M. L., Kapoor, M., Lee, S. L., and Tyner, K. M. (2017) The evolving landscape of drug products containing nanomaterials in the United States. Nat. Nanotechnol. 12, $523-529$.

(110) Korsmeyer, R. (2016) Critical questions in development of targeted nanoparticle therapeutics. Regener. Biomater. 3, 143-147.

(111) Bosetti, R., and Vereeck, L. (2011) Future of nanomedicine: Obstacles and remedies. Nanomedicine 6, 747-755.

(112) Katir, K., El Brahmi, N., El Kadib, A., Mignani, S., Caminade, A. M., Bousmina, M., and Majoral, J.-P. (2015) Synthesis of onion-peel nanodendritic structures with sequential functional phosphorus diversity. Chem. - Eur. J. 21, 6400-6408.

(113) Guidolin, K., and Zheng, G. (2019) Nanomedicines lost in translation. ACS Nano 13, 13620-13626.

(114) Ho, D., Wang, P., and Kee, T. (2019) Artificial intelligence in nanomedicine. Nanoscale Horiz. 4, 365-377.

(115) La-Beck, N. M., and Gabizon, A. A. (2017) Nanoparticle interactions with the immune system: clinical implications for liposome-based cancer chemotherapy, Front. Immunol. 8, DOI: DOI: $10.3389 /$ fimmu.2017.00416. 